\title{
Expansion del Acceso y Reformas del Currículo en la Educación Escolar Latinoaméricana: Implicancias para la Cohesión Social ${ }^{1}$
}

\author{
Expanding Accessibility to and Curricular \\ Reform in Latin American Schools: \\ Implications for Social Cohesion
}

\section{Accroître l'Accès aux Écoles et la Réforme des Programmes d'Études en Amérique Latine: Les Implications pour la Cohésion Sociale}

\author{
Cristián Cox \\ Pontificia Universidad Católica de Chile
}

RESUMEN

El artículo examina las políticas educacionales de la última década y media en América Latina desde la perspectiva de su contribución a la cohesión social. Luego de establecer la dirección de la relación entre educación y cohesión social, se evalúa el impacto de la sustancial expansión de las coberturas educativas en la región como una contribución a la cohesión social, al asegurar recursos simbólicos comunes a mayor proporción de la población, así como dinámicas de movilidad intergeneracional en educación que también contribuyen a la cohesión. En una segunda dimensión de impacto de la educación sobre la cohesión social, el artículo da cuenta de un análisis comparado de los currículos de formación ciudadana en siete países de la región - Argentina, Brasil, Colombia, Chile, Guatemala, México y Perú-, a los que se interroga en términos de sus orientaciones hacia la formación de capital social puente (entre grupos), o capital social vinculante (dentro de grupos) (Putnam, 2000), así como respecto a la relación que establecen con el pasado como base para la formación de una identidad común (nacional) entre grupos con marcadas diferencias socio-económicas. El análisis concluye que las orientaciones de los currículos de varios de los países examinados son problemáticas desde la perspectiva de cohesión social de la sociedad nacional.

Descriptores: políticas educacionales, currículos, capital social, cohesión social. 


\section{ABSTRACT}

The article examines Latin American educational policies in the last decade and a half from the perspective of their contribution to social cohesion. After establishing the direct relation between education and social cohesion, the author evaluates the impact of the substantial expansion of schooling in the region as a contributor to social cohesion. The latter takes place because education ensures the sharing of common symbolic resources among a large percentage of the population. It also facilitates dynamics of intergenerational mobility that also contribute to social cohesion. The article also presents the results of a comparative analysis of citizen formation curricula as developed in seven countries in the region: Argentina, Brazil, Colombia, Chile, Guatemala, Mexico and Peru. The central questions are based on the orientations taken by these countries with regard to the formation of bridging social capital (between groups), or of bonding social capital (within the groups) (Putnam, 2000), and to the relations the curricula establish with the past. The latter has as a point of reference the creation of a common identity (national) among groups exhibiting clear socio-economic differences. The analysis concludes that the curriculum orientation of the various countries examined in the study are related to the specific perspective of social cohesion that each national society holds.

Key words: educational policies, curricula, social capital, social cohesion.

\section{RÉSUMÉ}

Cet article examine les politiques éducatives latino-américaines de la dernière décennie et demie, du point de vue de leur contribution à la cohésion sociale. Ayant établi la relation directe entre l'éducation et la cohésion sociale, l'auteur évalue l'impact de l'expansion substantielle de l'instruction dans la région comme facteur de la cohésion sociale. Cette expansion a lieu parce que l'éducation assure le partage des ressources communes parmi un grand pourcentage de la population. Elle facilite aussi les dynamiques de mobilité intergénérationnelle qui contribuent également à la cohésion sociale. Cet article présente aussi les résultats d'une analyse comparative de programmes d'études de formation à la citoyenneté tels que développés dans sept pays de la région : Argentine, Brésil, Colombie, Chili, Guatemala, Mexique et Pérou. Les questions centrales sont basées sur les orientations prises par ces pays en ce qui concerne la formation d'un capital social relais (entre groupes) ou d'un capital social qui lie (au sein des groupes) (Putnam, 2000), et en ce qui concerne les relations que les programmes d'études établissent avec le passé. Ce dernier a comme point de référence la création d'une commune identité (nationale) entre les groupes qui manifestent de claires différences socioéconomiques. L'analyse conclut que l'orientation du programme d'études des divers pays examinés dans l'étude est reliée au point de vue spécifique de chaque société nationale au sujet de la cohésion nationale.

Mots-clés : politiques d'éducation, programme d'études, capital social, cohésion sociale.

\section{Introducción}

$\mathrm{L}^{\prime}$ A PREGUNTA SOBRE la cohesión social tiene como uno de sus ámbitos clave a la educación. Como quiera que se la defina, la cohesión social descansa sobre competencias de los individuos, características de las redes e instituciones que construyen sus relaciones sociales, y representaciones de lo común que, en su conjunto, integran simbólicamente una sociedad. Desde los tres puntos de vista, la secuencia formativa de seis, diez o doce años de la escolaridad obligatoria tiene una importancia decisiva: forma en, y distribuye socialmente, competencias y disposiciones que facilitan o dificultan la cooperación; inculcan un imaginario y unos valores comunes en que el conjunto de los grupos, clases, etnias, territorios, se reconocen y a los que confieren valor normativo, o bien, los desatienden o erosionan. 
La última década y media no tiene parangón en términos de activismo público y privado en la educación latinoamericana. Su resultado ha sido la expansión radical de las coberturas y el nivel en años de educación alcanzados por las nuevas generaciones, procesos de descentralización y criterios de focalización que impactan el modo de actuar tradicional del Estado en el ámbito educativo, y la omnipresencia de reformas curriculares que buscan modificar la experiencia de aprendizaje de las mayorías, adecuándola a lo que se entiende como los requerimientos de la globalización y la sociedad del conocimiento. Este conjunto de cambios ha sido interrogado desde criterios de calidad (o relevancia) y equidad, pero no aún desde el criterio de la cohesión social (Gajardo 1999; PREAL 2006; Carnoy 2007; Schwartzman 2007).

El interrogante acerca de la cohesión es diferente a las preguntas por la equidad o la inclusión. Mientras éstas tienen como foco las relaciones de desigualdad entre grupos respecto de un conjunto de recursos, el bienestar que resulta de ellos y las percepciones que tienen los individuos o grupos de sus posiciones relativas en el ordenamiento social, la cohesión social conduce a interrogar las características de los vínculos entre los grupos que hacen que una sociedad sea más integrada y más proclive a la cooperación que al conflicto. Tales vínculos, como se verá, dependen de características sistémicas del orden (socioeconómico, institucional y cultural) al que dan vida el conjunto de los grupos y sus interrelaciones (Sorj y Tironi 2007).

El propósito de este trabajo es dar cuenta de la evolución de los sistemas educativos de Latinoamérica en la última década y media desde la perspectiva de la cohesión social, con especial referencia a siete países: Argentina, Brasil, Colombia, Chile, Guatemala, México y Perú. ${ }^{2}$ El interrogante genérico es si los patrones de cambio observados en los sistemas escolares de la región contribuyen o no a la cohesión social, y cuáles han sido los alcances de las políticas educacionales al respecto.

\section{Educación y Cohesión Social}

Dos tradiciones principales dan cuenta del concepto de cohesión social. Por una parte la que se centra en los individuos y sus disposiciones hacia la cooperación y compromiso cívico, que dan origen a una sociedad civil vigorosa. Visión que surge y se desarrolla en la tradición política liberal e individualista que va desde De Tocqueville y su celebración del vigor del "asocianismo" Norteamericano de fines del siglo XVIII, a Coleman (1987) y Putnam (2000) y la centralidad de la 'confianza' y las 'redes' en su concepto de capital social. Por otra, aquélla en que la cohesión social es inseparable de unos arreglos institucionales que definen una distribución más o menos equitativa de recursos y poder, que se percibe como legítima y que tiene, en su referencia al estado y a la totalidad de un orden, características estructurales (Green, Preston, Janmaat, 2006); así como en su referencia a significados compartidos, por sobre las diferencias, un componente crucial de comunidad moral (Durkheim, 1977). Política e históricamente los referentes en este caso se incluyen en esquemas solidaristas propios de la tradición socialdemócrata europea.

El siguiente examen de las relaciones entre educación y cohesión social recurrirá 
a elementos de ambas tradiciones, preguntándose sobre la experiencia educativa y la formación de competencias y disposiciones de los individuos hacia la cooperación, la asociatividad y la confianza. Se interrogará, también, acerca de la distribución social de la educación, lo cual es básico para la cohesión desde una perspectiva societal.

\section{Cohesión Intra-Grupos y entre Grupos: Tipos de Capital Social}

Robert Putnam (2000) distingue entre dos formas de capital social: aquel basado en relaciones de confianza intragrupo o comunidad (capital vinculante)-, y el que se funda en, o resulta de, relaciones de confianza entre grupos, intercomunidades -(capital puente), y lo operacionaliza en cinco dimensiones que dan una idea del alcance del concepto: vida organizacional comunitaria, involucramiento en asuntos públicos (votación en elecciones presidenciales), voluntariado comunitario, sociabilidad informal y confianza social. ${ }^{3}$ Si se asume la cohesión social en un sentido societal, no solo grupal, el que importa básicamente es el capital puente, ya que altos niveles de asociatividad (capital vinculante) pueden darse junto con altos niveles de desconfianza y fragmentación social (Fukuyama 1995). Esto mismo ha sido conceptualizado en términos de la diferencia entre cohesión social y cohesión societal: la primera está relacionada con la cohesión al nivel de una comunidad, mientras la última se refiere a redes, relaciones de confianza y patrones de reciprocidad que facilitan la acción colectiva y vinculan a los miembros de comunidades particulares con terceros. Países que son ricos en capital social a nivel de comunidades no son necesariamente cohesivos a nivel societal; también, algunos tipos de asociación pueden ser beneficiosos para la más amplia confianza y armonía societal, en cambio otros no (Green et al. 2003).

Un sistema escolar nacional es la institución crucial en sociedades complejas y desiguales, en tanto permite la construcción de las bases culturales del capital social puente, sustento de la cohesión societal. También, por cierto, es fundamental en la construcción de las competencias fundantes del capital social vinculante, pero este se establece asimismo sobre otro pilar, el de la socialización familiar y las formas de asociatividad informales intra-grupo. En la construcción de las capacidades de relación con los distintos, la educación formal es el ámbito institucional decisivo. Y son las capacidades de confianza entre grupos, entre comunidades, a nivel societal, las que permiten procesar conflictos por medios políticos, bajar los llamados costos de transacción en la economía y producir las capacidades de cooperación de un orden cohesivo.

En lo que sigue se utilizarán las distinciones anteriores para el análisis de los currículos, asociando objetivos y contenidos de ciudadanía política a la formación de capacidades de capital social puente, y objetivos y contenidos de civismo y convivencia a la formación de capacidades de capital social vinculante. Un factor que, como se verá, discrimina entre los currículos escolares de los siete países estudiados, es el que dice relación con la naturaleza del equilibrio o prioridades que se establecen entre estos dos tipos de objetivos y contenidos. 


\section{Dirección de la Relación Educación-Cohesión Social; Variaciones y Paradojas}

¿Cuáles son las relaciones entre educación y cohesión social? El análisis de Putnam sobre el capital social en los Estados Unidos muestra que los últimos dos años de college hacen el doble de diferencia sobre la confianza y la pertenencia a grupos o asociaciones que los primeros dos años de high school, con independencia de género, raza y generación, estableciendo entonces una relación positiva entre educación y capital social. Así, respecto de las personas altamente educadas, Putnam sostiene que "es mucho más probable que sean participativos y tengan confianza, en parte porque tienen una mejor situación económica, pero principalmente por las habilidades, recursos e inclinaciones que les fueron impartidos en el hogar y en la escuela" (cit. en Green et al. 2006: 28). Para el mismo Putnam, como para Coleman, la relación opera asimismo en la dirección inversa, y también positivamente: a mayor capital social o redes comunitarias sosteniendo a estudiantes como a sus escuelas y colegios, mejores resultados educativos (Putnam 2000; Coleman \& Hoffer 1987). ${ }^{4}$

El análisis de los datos de la encuesta ECosociAL-2007 para Argentina, Brasil, Colombia, Chile, Guatemala, México y Perú revela el mismo patrón observado por Putnam: a mayor educación, aumenta la proporción de personas cohesivas. Esto resulta de un índice que combina los siguientes indicadores: (1) la confianza que el individuo dice tener en los otros; (2) el sentirse parte de una mayoría; (3) el trabajar por iniciativas comunitarias; y (4) el orgullo patrio (Crouch et al. 2007). ${ }^{5}$ Como revela el siguiente gráfico, la proporción de población urbana cohesiva en los países de ECosociAL-2007 varía entre 18 y $20 \%$ en las dos generaciones de personas con una educación inferior a la primaria completa, elevándose a alrededor de $32 \%$ entre las personas con educación superior.

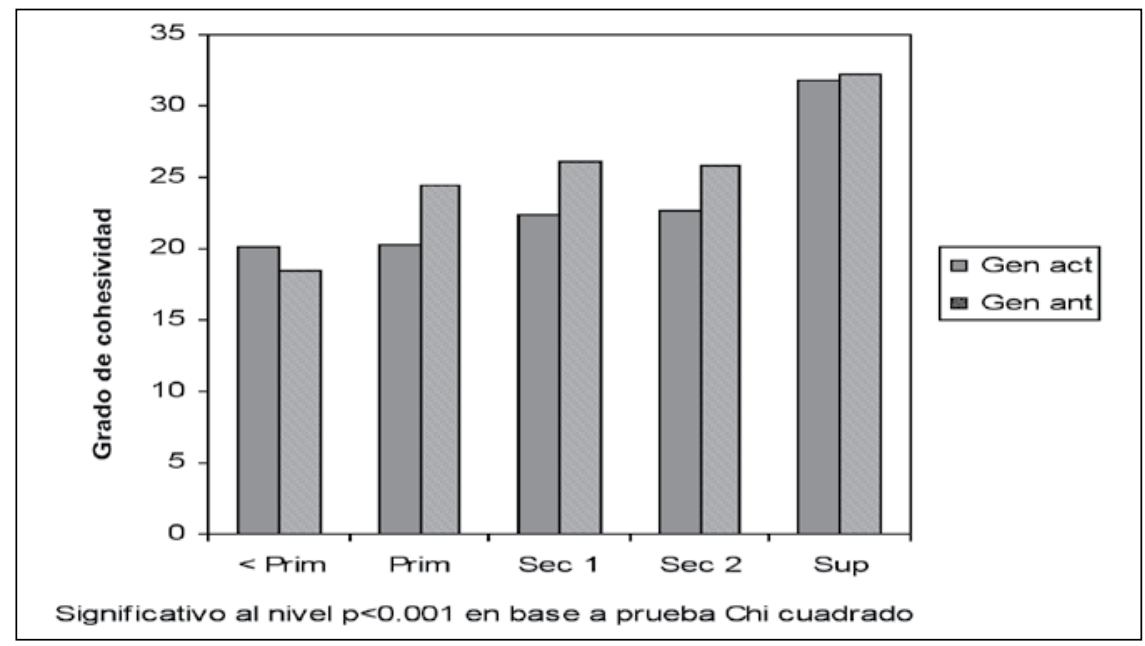

Gráfico 1: Niveles educacionales y cohesividad en ECosociAL-2007

Fuente: Crouch et al. (2007) a partir de los datos ECosociAL-2007.

Gen act.: Generación actual

Gen ant.: Generación anterior 
El mismo análisis, desagregado por años de educación cursado y en base a los datos de Latinobarómetro 2005, revela que no es hasta la educación universitaria, o por lo menos secundaria-alta, donde se nota una relación no solo estadísticamente fuerte sino sustantivamente fuerte entre educación y cohesividad. Es de notar la sistemática diferencia en ambos gráficos -que provienen de fuentes diferentes-, respecto de la cohesividad en las dos generaciones comparadas, lo que sugiere factores de período interesantes de investigar.

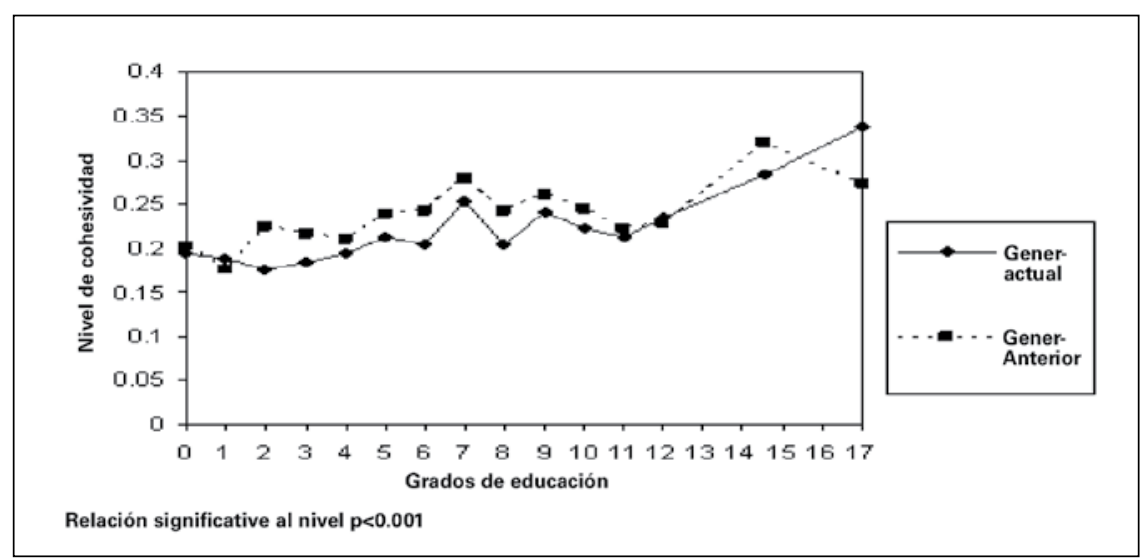

Gráfico 2: Relación entre educación y cohesividad (Conjunto de Países de Latinoamérica, 2005) Fuente: Crouch et al. (2007) a partir de datos Latinobarómetro 2005.

La cohesividad en los individuos o en comunidades determina directamente niveles de capital social, pero no necesariamente la cohesión social. Esta, como se adujo, involucra no solo redes y confianza dentro de grupos sino entre ellos, lo que implica significados compartidos y cuestiones de poder y distribución de recursos, instituciones, ideologías y culturas. La distinción aludida es la que ayuda a despejar la paradoja de que Estados Unidos exhiba simultáneamente niveles crecientes de educación y al mismo tiempo erosión de su cohesión social; que pueda tener proporciones altas de individuos con disposiciones pro 'confianza' y 'asociación', y al mismo tiempo fragmentación y conflicto a nivel societal.

El capital social no necesariamente escala hacia arriba desde el nivel de la comunidad al nivel de la sociedad global. La presencia en el nivel individual de 'cohesividad', es condición necesaria pero no suficiente de la cohesión social, y ésta debe ser considerada en términos sistémicos, como indican Sorj y Tironi (2007: 118-119):

Cohesión social es la capacidad dinámica de una sociedad democrática para absorber el cambio y el conflicto social mediante una estructura legítima de distribución de sus recursos materiales y simbólicos, tanto a nivel socioeconómico (bienestar), sociopolítico (derechos) y sociocultural (reconocimiento), a través 
de la acción combinada de los mecanismos de asignación del Estado, del mercado, de la familia, de la sociedad civil y de las redes comunitarias.

La definición anterior implica que no hay un modelo único de cohesión social ni que esta se puede concebir como medible en una escala unidimensional. Es lo que encontró la investigación comparada de Green et al. (2006): que los factores clave identificados por la teoría del capital social como decisivos para la cohesión -asociatividad, tolerancia, confianza en otros y en instituciones, civismo y participación política - no co-variaban entre países. En particular, que niveles de tolerancia y asociatividad no se asocian en todos los países con alta confianza y bajos niveles de criminalidad. Estados Unidos, por ejemplo, tiene altos niveles de asociatividad y de confianza, pero alto nivel de criminalidad; los países nórdicos, en cambio, exhiben altos niveles de confianza y moderados niveles de asociatividad. "No podemos definir una forma única de cohesión social -concluyen los autores -: parecería que hay múltiples tipos de cohesión social, regímenes de cohesión social diferentes." (Green et al. 2006: 175).

\section{Distribuciones y Formación}

Los efectos de la educación sobre la cohesión social son multinivel. Ellos están anidados en estructuras, contextos y relaciones sociales que obligan a un análisis que vaya más allá de la noción lineal respecto de qué procesos formativos efectivos afectan positivamente el capital de conocimientos, valores y actitudes de las personas -los que a su vez producen disposiciones al involucramiento social y cívico, afectando positivamente a la cohesión societal. Esta dependerá no solo de lo que porta cada individuo como capital humano, sino también de la comparación de este con los niveles educativos de su grupo, de las configuraciones institucionales que estructuran un orden y, muy decisivamente, de los sistemas de representaciones y creencias que fundan o no la adhesión al mismo.

La línea interpretativa que se desarrolla en adelante es que la educación impacta sobre la cohesión social a través de dos vías fundamentales: indirectamente, a través de la distribución de competencias (y por tanto, ingresos, oportunidades y estatus); y directamente, a través de la formación en la nueva generación de tales competencias y su socialización en diferentes valores, visiones de la sociedad e identidades (Green et al. 2006).

En lo que sigue se examinará evidencia preliminar sobre ambas dimensiones desde la perspectiva de la cohesión social: en primer término, las políticas públicas en educación de la última década y media y sus relaciones con la evolución de las coberturas y niveles de equidad de la educación; luego, las reformas del currículo para la formación ciudadana, ventana privilegiada para el examen de las orientaciones oficiales respecto a relaciones clave para la construcción escolar de las bases culturales de la cohesión social. 


\section{Políticas Educacionales de los Noventa, Distribución de la Educación y Cohesión Social en Latinoamérica}

La base sociocultural de la cohesión social tiene directa relación con la naturaleza y extensión de lo compartido por los grupos como experiencia común. La extensión social y duración temporal de una experiencia escolar común posee desde esta perspectiva una importancia decisiva al constituir la condición fundamental para el funcionamiento de una sociedad compleja y diversificada: la existencia de unas capacidades comunicativas compartidas. Desde este punto de vista, la pregunta que se debe formular respecto de las políticas educacionales de la última década y media en Latinoamérica alude al impacto que ellas han tenido tanto en la expansión como en la distribución de lo común, vía la experiencia educativa de las mayorías.

Como se ha mencionado, el período del cambio de siglo no tiene precedentes en términos de activismo público y privado en educación. Con diferencias sustanciales entre países, los procesos de reforma tienen, sin embargo, una marca compartida: todos ellos coinciden con el período más largo de la historia de la región de gobiernos elegidos por la vía democrática, un accionar estatal profundamente influído por modelos de ajuste estructural y liberalización económica -que acompañan al llamado "consenso de Washington" -, y la influencia cultural de las presiones que traen consigo la globalización y el advenimiento de la sociedad de la información.

En este marco mayor, las políticas educacionales del período 1990-2005 presentan al menos cinco componentes distintivos: 1) expansión y racionalización del gasto; 2) descentralización de la gestión; 3) programas focalizados en categorías de la población; 4) reformas curriculares; 5) sistemas de evaluación de resultados, información y rendición de cuentas. (Gajardo 1999; Kaufman y Nelson 2005; PREAL 2006; Carnoy 2007; Grindle 2007). En este trabajo se examinarán los cuatro primeros componentes con el propósito de iniciar una reflexión acerca de sus impactos sobre la cohesión social.

\section{Evolución y Asignación del Gasto}

El nivel y evolución del gasto en educación es, simultáneamente, un retrato de las prioridades gubernamentales y el marco condicionante básico de sus posibilidades de expansión. Desde ambos ángulos, y para el conjunto de la región, el período reciente brinda alta prioridad a la educación y expansión del gasto. Como proporción del PIB, el gasto público en el sector aumentó de 2,7\% en 1990 a 4,3\% en el período 2002-2003. Comparado con el resto del mundo, el nivel alcanzado es superior al promedio de los países de ingresos bajos y medios; se estima que si a esto se agrega el gasto privado, el porcentaje del PIB destinado a educación en Latinoamérica llega incluso al 10\% (PREAL 2006).

En el período considerado, el gasto por alumno subió en la mayoría de los países de la región. El mayor gasto es asimismo sometido a procesos de estandarización y racionalización que acompañan la modernización de la gestión en el marco de procesos de descentralización de la misma. El caso de algunos países es ilustrativo: Chile asigna 
recursos sobre la base de una subvención por alumno idéntica en todo el país, a la que agrega luego factores pro equidad; Brasil modificó el mecanismo de asignación a estados y municipios, sobre la base del cálculo del costo anual por alumno, modificando patrones históricos de desigualdad al respecto; en Argentina, se observan dinámicas similares de reparación de inequidades entre provincias, aunque inefectivas (Carnoy et al. 2004); y Colombia especifica los rubros en que las unidades descentralizadas pueden gastar fondos de transferencias centrales (Filgueira et al. 2006).

En términos simplificados, se puede concluir que el mayor gasto y el mejoramiento de su asignación, en términos de equidad entre unidades administrativas y territorios, apuntaron tanto a la expansión de las oportunidades educativas como a la mejora de su distribución. Ambos objetivos se han visto reflejados en el período en una expansión marcada de coberturas y un aminoramiento de las desigualdades educativas en términos de años de educación completados por diferentes grupos de ingreso.

\section{Cambio en Papel del Estado}

En términos de reformas institucionales, el proceso más importante y de mayor presencia en las reformas educacionales recientes de la región es la descentralización. El traspaso de poder y responsabilidades desde el gobierno central se ha entendido de diferentes maneras en los distintos países: como transferencia hacia gobiernos subnacionales, como es el caso de Chile, Argentina y Brasil; como transferencia a una combinación entre gobierno nacional y gobierno subnacional, como en Colombia y Bolivia; o un traspaso directo a las escuelas, como es el caso de Nicaragua y El Salvador (Di Gropello 2004). Como sea, la descentralización tiene significados vastos y contradictorios desde una perspectiva de cohesión social. Ella da origen a un profundo cambio en el funcionamiento del Estado y de su modelo de acción en el campo de la educación. El modelo histórico de construcción de identidad y cohesión social a través de la educación basado en la homogeneidad, la verticalidad y el control centrales, comienza a combinarse (de maneras cuya consistencia varía grandemente entre los diferentes países) con otro modelo, todavía en ciernes, pero cuyo leit-motiv es la diversidad, la horizontalidad y el control local (Iaies y Delich 2007)

El proceso de descentralización descrito implica un cambio histórico. Para las élites del siglo XIX, la educación pública fue el instrumento fundamental de creación y desarrollo de la nación a través de la inculcación de un ideario moral que tenía a la misma nación y su unidad como referente primordial. La noción de una experiencia formativa común, universal e idéntica para todos, que disuelve particularismos de todo tipo en el crisol de la escuela pública, ordenó la organización centralizada de la provisión de educación y los atributos acompañantes de instituciones, normativa, currículum y formación de profesores definidos nacionalmente y de acuerdo a normas comunes. El término normal ordenó la mayoría de los atributos de la educación pública: la norma de construcciones, pupitres y materiales educativos; las escuelas normales para la formación de los maestros; la normativa curricular; la norma burocrática única y de aplicación nacional para regimentar al servicio educativo en su conjunto, en la lógica jurídica y burocrática de igualdad de todos ante la ley. 
Con ese objetivo, institucionalmente el sector educativo se organizó en términos de una conducción centralizada, con una cabeza que tomaba decisiones únicas y universales; una estructura vertical con toma de decisiones solo en la cúpula que debía "bajar" prescripciones claras y sin espacio de interpretación; un alto grado de regulación a través de normas detalladas, específicas y fácilmente auditables; un currículum y libro de texto únicos, instrumentos clave de la homogeneización; unas directrices didácticas detalladas; ${ }^{6}$ y una permanente presencia de rituales que celebraban a la Nación y exaltaban los sentimientos primarios de un espíritu nacional, al punto de ocupar un lugar prominente en la experiencia escolar común.

En síntesis, puede sostenerse que, en su desarrollo original, las características constitutivas de los sistemas educativos, más allá de notorias diferencias entre países, provienen

(...) del hecho de que aquellos sistemas estaban plenamente avalados por una cultura política que priorizaba la cohesión de la sociedad nacional, por modelos de gestión de política pública orientados a lograr la homogeneidad y por el grado de legitimidad con que se desarrolló el proceso general de construcción de la dirigencia que ejercía el poder central a nivel nacional, cuya fuerza se transmitía 'desde arriba', y llegaba 'hasta abajo', invistiendo la autoridad de los maestros (...) (Iaies y Delich 2007: 19).

\section{Descentralización y Focalización}

Al iniciarse la década de 1990, CEPAL y UNESCO elaboran un diagnóstico crítico de los sistemas nacionales de educación, capacitación, e investigación científica y tecnológica de Latinoamérica, y desarrollan una propuesta de cambio que equivale a la formulación de un nuevo paradigma de políticas en educación para la región. Esto se basó en un juicio sobre el período que va desde la posguerra hasta fines de los años ochenta: se habían alcanzado grandes logros en el acceso, pero estos estaban segmentados socialmente y con resultados de aprendizaje de deficiente calidad, desconectados de los requerimientos de la sociedad. (CEPAL-UNESCO 1992). En el centro del diagnóstico está una crítica a la institucionalidad y gestión centralizada y burocrática de los sistemas escolares y su creciente desconexión con los nuevos requerimientos del desarrollo socioeconómico. Este diagnóstico definió como factores específicos a resolver la administración de los sistemas, que "se han ido burocratizando al punto de haberse transformado cada una en un segmento cerrado que no le rinde cuentas a nadie salvo a sí mismo", y llevando a una "la radical separación entre el sistema de formación de recursos humanos y las necesidades del desarrollo" (CEPAL-UNESCO 1992: 77).

\section{a) Cambios en la estrategia: descentralización}

El camino que siguen muchas reformas luego de tal diagnóstico es el de la descentralización y la autonomía de los centros. Adicionalmente, se plantea el tránsito desde políticas orientadas a producir la homogeneidad hacia otras que promuevan la 
diversidad; el giro desde la norma y las respuestas lentas y uniformes hacia las iniciativas bottom-up, con incentivos y apoyos institucionales orientados a fomentar la flexibilidad de los sistemas y sus capacidades de respuesta rápida. ${ }^{7}$

La nueva estrategia propuesta tuvo como objetivos clave la competitividad y la ciudadanía (esta última con explícita referencia a la equidad y la cohesión social), mediante la descentralización de la gestión de los sistemas y su apertura al medio externo. Esta estrategia recibió un impulso fundamental para su implementación a través de los proyectos de mejoramiento de la calidad y equidad financiados total o parcialmente por el Banco Mundial y el Banco Interamericano de Desarrollo. El rationale de estos proyectos viene de categorías propias de la economía, que fundamentan la descentralización de la educación a base de mejoramientos de la eficiencia técnica y social de la gestión, para lo cual es necesario mejorar el flujo de información para la toma de decisiones acercando al decididor respecto al problema, y mejorar la accountability acercando al mandante al mandatario o cliente/agente (Winkler y Gershberg 2000; World Bank 2004; Di Gropello 2004).

Desde la perspectiva de la cohesión social, los efectos de los procesos de descentralización son ambivalentes. Por un lado erosionan el poder unificante e igualizador del centro de los sistemas, y por lo mismo, crean un terreno favorable para la expansión de las inequidades de base, lo cual por cierto tiene efectos negativos sobre la cohesión. Por otro lado, los procesos de descentralización pueden traer mayor eficiencia, participación y accountability, lo que podría ser positivo para la cohesión. Con todo, los efectos potenciales de la descentralización sobre la cobertura, calidad y relevancia de la educación son superiores que sus efectos sobre la cohesión, en especial si las energías locales se despliegan en sociedades altamente desiguales y donde el Estado tiene capacidades menguadas de nivelar las diferencias en el campo de juego.

Este cuadro de resultados ambivalentes de la descentralización desde el punto de vista de la cohesión, aunque sesgados hacia un impacto negativo, no es completo si no se los considera junto a las políticas de focalización.

\section{b) Cambios en la estrategia: focalización}

La implementación estatal de programas educativos focalizados en grupos específicos con desventajas, sean sociales o educativas, caracteriza también a las políticas del período. Programas como Escuela Nueva, de Colombia, 900 Escuelas de Chile, Plan Social de Argentina, Bolsa Escola de Brasil, Abatir el Rezago Educativo (Programa PARE) de México, entre decenas de otros a lo largo y ancho de la región, representan un nuevo paradigma de acción estatal en educación. El origen de estos programas radica en el descubrimiento de que las normas universales en este ámbito favorecen a quienes ya son los más favorecidos, y que la producción de resultados de aprendizaje comparables entre grupos con muy distintos capitales culturales de origen supone experiencias educativas diferenciadas. Los programas, en general, logran buenos resultados, tanto en términos de inclusión como en términos de calidad o resultados de aprendizaje, contribuyendo a aminorar distancias entre los logros de los más desfavorecidos y los promedios nacionales (Carnoy 2007).

Es necesario destacar la ambivalencia de los programas focalizados en términos de 
lógicas de integración sociocultural. Por un lado representan la priorización estatal de metas de inclusión y equidad. Por el otro, sin embargo, representan un declive de las capacidades de integración simbólica que representaba el accionar estatal en el paradigma homogeneizador y centralista histórico, ahora centrado en la diferenciación y especialización de sus metas, medios e instituciones, sumado al cambio de su ethos legal-nacional por una lógica de industria de servicios (Dubet 2006).

En el balance global, ¿cuáles serían los resultados en términos agregados de las tendencias hacia la fragmentación y diversificación que conllevan los procesos de descentralización, por un lado, y los procesos de inclusión empujados por los programas focalizados de atención educativa a la pobreza y la marginación, por el otro, en un marco de expansión de las coberturas de los sistemas y extensión de la escolaridad obligatoria en la mayoría de los países?

\section{Distribución de la Educación}

En términos de distribución social de la experiencia educativa, el balance global es inequívoco: en la región ha habido una expansión sustantiva de la experiencia educacional común, con un impacto claro en la disminución de la desigualdad educativa en términos de años de escolaridad y en la aceleración de los procesos de movilidad educativa intergeneracional. Esta dinámica se funda en una expansión consistente de la cobertura educacional, que abarca más de cuatro décadas. El Gráfico 3 ofrece una visión comparada de la completación de estudios entre seis generaciones para 12 países, categorizados según su patrón de expansión de la escolarización primaria y secundaria.

Las generaciones en el eje horizontal y la proporción de cada una de ellas que completa el nivel educativo de que se trate, refleja las capacidades de inclusión de los sistemas escolares de los diferentes países desde la década de 1940 (en la que se educó la generación que en 2005 tenía '65 y más' años), hasta mediados de los Noventa (en la que concluyó su educación el grupo de edad '18 a 24' años). Los países que masificaron su educación primero (y que tienen las mayores coberturas desde el inicio) -Argentina, Chile y Uruguay, hoy han universalizado la educación primaria (tasas sobre 90 por ciento de completación de estudios). Ya en la década de los Setenta habían logrado que más del 80 por ciento de la generación de '35 a 44' años completara la primaria; mientras que esto sigue siendo en el presente un logro distante para los otros países, que al final de los Noventa tenían entre un 60 por ciento (Grupo 2) y un 65 por ciento (Grupo 3) de la cohorte, completando su educación primaria. En el caso de la educación secundaria, para el primer grupo de países, casi un 20 por ciento de la generación de los abuelos, 40 por ciento de la de sus hijos, y el 60 por ciento de la de sus nietos concluyó su enseñanza secundaria, mientras que los restantes países obtuvieron recién en la década de los Noventa que 20 por ciento de la cohorte más joven completara este nivel. Más allá de los muy diferentes puntos de partida, los patrones de crecimiento son similares a lo largo y ancho del continente y a través de medio siglo de una historia de fuertes cambios políticos, económicos y sociales. La caracterización del célebre historiador Fernand Braudel de las "breves, rápidas y nerviosas oscilaciones" (Braudel, 2002, p.18) que distinguen la historia de los eventos políticos de la historia 
Porcentaje con primaria completa

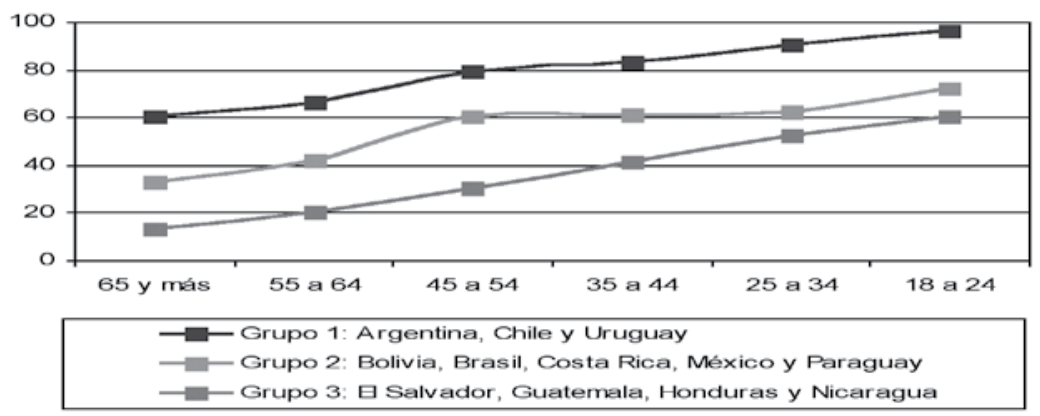

Porcentaje con secundaria completa

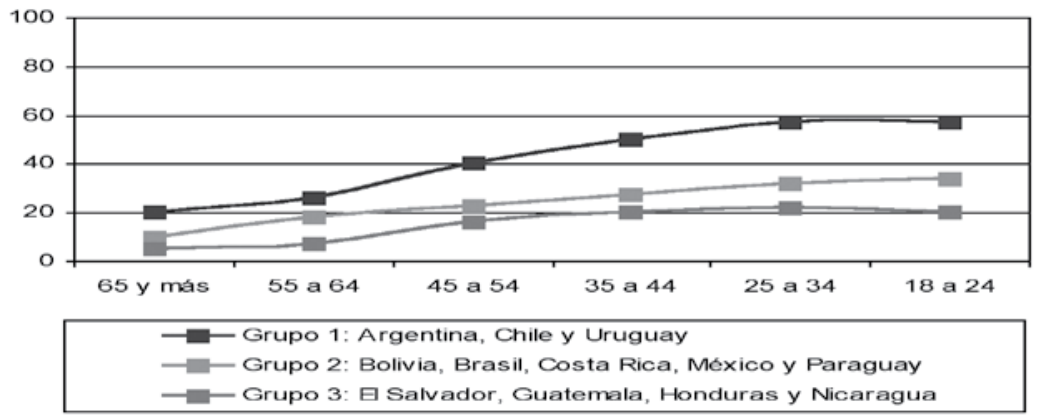

Gráfico 3: Comparación de completación de estudios primarios y secundarios por grupos de edad para tres grupos de países de América Latina (2006)

Fuente: IIPE-OEI (2006), Gráfico 5.

social, parece apropiada aquí: la consistente marcha intergeneracional de la educación procediendo a paso más lento y seguro que la historia política.

La extensión sustantiva de la experiencia educativa en término de años de escolarización de las nuevas generaciones es, sin embargo, diferenciada socialmente, tal como lo muestra el Gráfico 4. En éste se observa cómo la expansión de las coberturas educativas, medida a través de la conclusión de estudios en los niveles primario, secundario y terciario, en el conjunto de la región (18 países) en el período 1990-2005, es estructurado según el nivel educacional de los padres. En el nivel primario hay un incremento de la proporción que concluye este nivel entre los hijos de padres con menor nivel educativo (primaria incompleta), acortando la brecha con el resto; en el nivel secundario hay un aumento generalizado de los que concluyen, como lo muestra el alza del conjunto de la distribución correspondiente a 2005, comparada con la curva que representa la distribución de 1990, con mantención, sin embargo, de las diferencias que afectan especialmente a los dos grupos cuyos padres tienen menor educación (primaria incompleta y hasta secundaria incompleta). No se registran mejorías en la educación terciaria, en la que las dos curvas prácticamente coinciden. 
A. Conclusión de la educación primaria entre jóvenes de 15 a 19 anõs

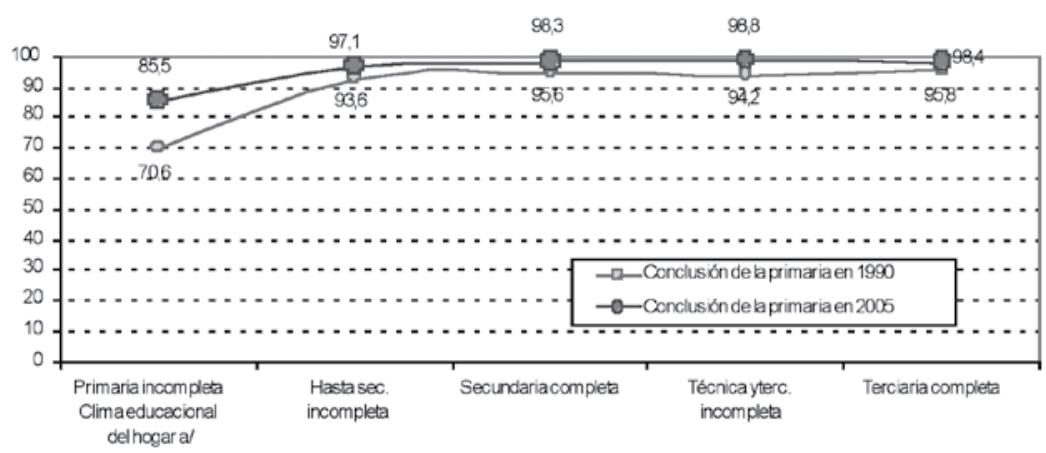

B. Conclusión de la educación secundaria entre jóvenes de 20 a 24 anõs

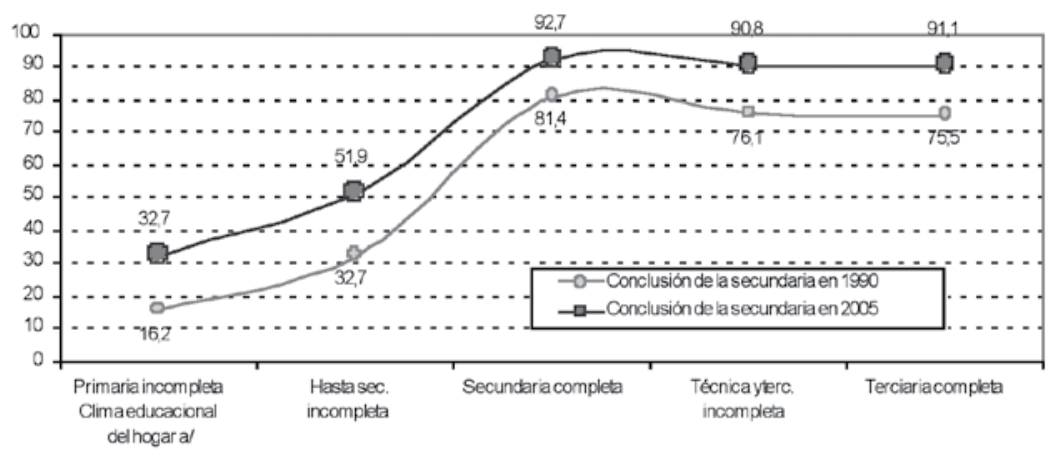

C. Conclusión de la educación terciaria entre jóvenes de 25 a 29 anõs

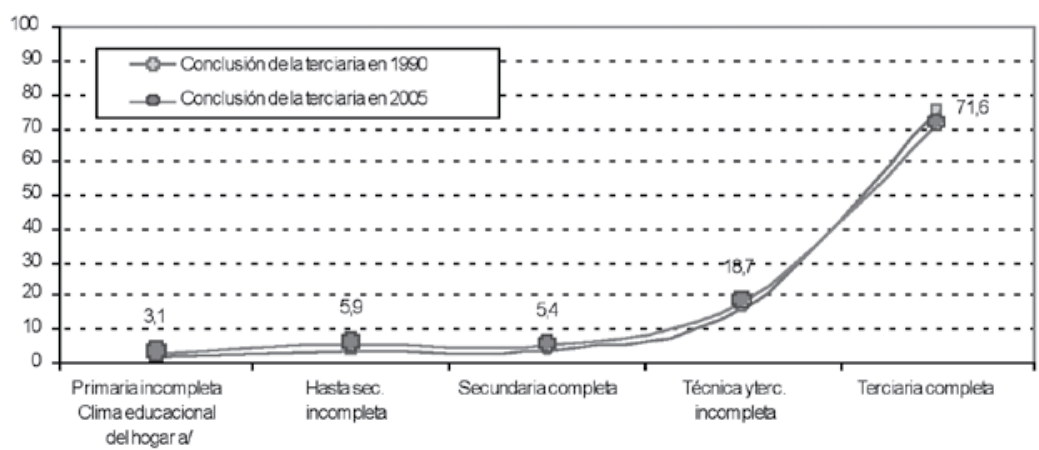

Gráfico 4: Evolución de la Conclusión Educativa entre Jóvenes de Distintos Grupos de Edad según el Clima Educacional del Hogar - comparación de dos décadas (Porcentaje para 18 países de América Latina)

Fuente: CEPAL (2007) Gráfico III.7, p.23, sobre tabulaciones especiales de las encuestas de hogares de los paises. al Promedio de años de estudio del jefe de hogar y su cónyuge, como aproximación a la educación de los padres. b/ La información referida a la comparación 1990-2005 excluye Guatemala, y considera ocho ciudades principales y El Alto en Bolivia, y las zonas urbanas de Argentina, Ecuador, Paraguay y Uruguay. 
Se puede así concluir que una resultante fundamental de las políticas educacionales de la última década y media es el aumento de las coberturas y la retención escolar, en términos que cambian sustancialmente el nivel de desigualdad educativa en años de educación completados entre la generación actual y la precedente. Este cambio generacional radical de la desigualdad lo ilustra muy bien la Tabla 1.

\begin{tabular}{|l|c|c|}
\hline & $\begin{array}{c}\text { Coeficiente Gini de grados de } \\
\text { educación Generación de padres }\end{array}$ & $\begin{array}{c}\text { Coeficiente Gini de grados de } \\
\text { educación Generación actual }\end{array}$ \\
\hline Argentina & 0,47 & 0,22 \\
\hline Bolivia & 0,74 & 0,38 \\
\hline Brasil & 0,56 & 0,40 \\
\hline Colombia & 0,55 & 0,34 \\
\hline Chile & 0,44 & 0,21 \\
\hline Ecuador & 0,47 & 0,34 \\
\hline México & 0,60 & 0,34 \\
\hline Costa Rica & 0,53 & 0,36 \\
\hline El Salvador & 0,62 & 0,51 \\
\hline Guatemala & 0,72 & 0,55 \\
\hline Honduras & 0,72 & 0,48 \\
\hline Nicaragua & 0,74 & 0,48 \\
\hline Panamá & 0,54 & 0,31 \\
\hline República & 0,59 & 0,39 \\
\hline Dominicana & 0,45 & 0,31 \\
\hline Paraguay & 0,67 & 0,37 \\
\hline Perú & 0,41 & 0,25 \\
\hline Uruguay & 0,63 & 0,26 \\
\hline Venezuela & $\mathbf{0 , 5 8}$ & $\mathbf{0 , 3 6}$ \\
\hline Promedio & 0 & \\
\hline
\end{tabular}

Tabla 1: Cambios generacionales en la distribución de la educación (En cuanto a grados completados)

Fuente: Crouch et al. (2007) a partir de datos de Latinobarómetro 2005.

La Tabla 1 exhibe los coeficientes Gini de los grados de educación manifestados por los entrevistados en la encuesta Latinobarómetro 2005, y lo que ellos señalan respecto al grado de educación de sus padres. Los datos son reveladores de un cambio sustancial: se registra una mejoría de 22 puntos porcentuales $(37 \%)$ en la igualdad de la distribución de los grados completados de una generación a la otra. La movilidad educativa intergeneracional medida por ECosociAL-2007 es consistente con los antecedentes referidos. La evidencia recolectada por esta encuesta indica que la proporción de hombres de 25 años y más que reporta tener un nivel educativo mayor que sus padres alcanza el 46\%, mientras que las mujeres que declaran lo mismo respecto de sus madres, un 49\% (Valenzuela et. al 2008). 
En la generación anterior, indican Crouch et al., "la distribución de los grados de educación era más o menos igual o peor que la distribución del ingreso (que oscila, y hace décadas oscila, alrededor de 0,55 en América Latina), hoy la distribución de los grados completados anda 20 puntos porcentuales mejor que la distribución del ingreso" (Crouch et al. 2007: 14). Esto tendría algún impacto sobre la proporción en la población de individuos cohesivos. ${ }^{8}$ Los autores estiman que una mejoría de 20 puntos en la desigualdad educacional generaría una mejoría de unos siete puntos en el porcentaje de gente que es cohesiva. Este impacto no es leve, "ya que el porcentaje promedio de 'cohesividad' (para el conjunto de países de la región) es de $22 \%$. Un aumento de 7 puntos, cuando el promedio es 22, es altamente significativo" (Crouch et al. 2007:14).

En fin, el gran progreso en la distribución de la educación parecería tener un efecto claramente positivo sobre la cohesión societal. Esto está en línea con el análisis y la evidencia internacional comparada de Green et al. (2006).

\section{Nuevos Currículos: Implicancias para la Cohesión}

La segunda vía de impacto de la educación sobre la cohesión social es la formación en determinadas competencias, valores e imaginarios, los cuales pueden facilitar o no la cooperación y la cohesión. Para examinar una dimensión estructurante (y 'topdown') de tal formación, se abordará el currículo oficial: o la definición estatal de las oportunidades de aprendizaje que organizará cada sistema escolar nacional. Desde la perspectiva de la cohesión social es de importancia capital evaluar las características del imaginario común al que recurre la educación para establecer los significados compartidos, bases de la confianza y la cooperación cívica.

Se analizan a continuación contenidos de los currículos oficiales vigentes, es decir, la prescripción de lo que el sistema escolar debe facilitar como oportunidades de aprendizaje, respecto a dimensiones relevantes para la cohesión social, definidos entre mediados de los Noventa y 2005. Las características político-institucionales de la generación del currículo en cada país constituyen un tema vertebral para responder interrogantes sobre su representatividad, legitimidad y efectividad (o sea, acerca de su "bajada" a las aulas): estos aspectos, sin embargo, aquí no son abordados. Por otro lado, como se sabe, el currículo oficial no es sinónimo de currículo implementado -es decir, transformado en prácticas de aula por los profesores- y menos lo es aún, del logrado o incorporado como aprendizaje por niños y jóvenes.

En lo que sigue, el análisis se restringe al currículo prescrito. El valor del mismo -a pesar de su distancia respecto de las dos traducciones que experimenta en su paso a las aulas y a la incorporación en las personas vía aprendizaje- está en que tal prescripción curricular refleja en forma elocuente la definición que una sociedad hace sobre lo que juzga esencial transmitir a la próxima generación, es decir, su propio futuro como sociedad. Simultáneamente, constituye el marco regulador clave de la experiencia educativa que organizan los sistemas escolares públicos, al definir los objetivos y contenidos que enmarcan el quehacer de los profesores, los contenidos de los libros de texto y la evaluación, y en los sistemas más coherentes, también la formación 
inicial de los profesores y las actividades de educación continua de los mismos. Si el currículo logrado, incorporado en las personas, es traducción del prescrito, bien vale la pena comenzar por este al examinar consecuencias de la experiencia educativa sobre la cohesión social.

La experiencia escolar prepara explícitamente para la vida en común, tanto con otros inmediatos (capital social vinculante) como lejanos (capital social puente). El currículo prescrito de un sistema escolar nacional, como definición oficial de los objetivos y contenidos formativos de tal experiencia, corresponde a la visión de la sociedad sobre sí misma que se procura transmitir a la nueva generación y, por tanto, acerca de tal vida en común y sus nociones y valores constitutivos.

Se han considerado las definiciones curriculares nacionales de México, Guatemala, Colombia, Brasil, Perú, Argentina y Chile. Aunque las denominaciones varían, así como también las formas de organizar objetivos y contenidos de aprendizaje, las áreas examinadas del currículo son las de historia y ciencias sociales, educación cívica y lenguaje, y en algunos casos, ética y orientación. Asimismo, se han abordado los objetivos transversales del currículo, que en muchos casos concentran las definiciones nacionales sobre los valores y competencias relacionales a inculcar.

La pregunta que guió el análisis es si las oportunidades de aprendizaje, que el currículo define, contribuyen o no a generar en la nueva generación los conocimientos, habilidades y disposiciones que favorecen la cohesión social, entendida esta a nivel macro, es decir, de la sociedad en su conjunto. Esto llevó a interrogarse por tres dimensiones del currículo, dirigido explícitamente a la formación para la vida en sociedad. En primer término, cuál es la presencia que tienen en el mismo los objetivos y contenidos que apuntan a una identidad común o comunidad moral; vale decir, aquello que trasciende grupos y modos de vida particulares. Segundo, cómo se combinan en las prescripciones del currículo, objetivos y contenidos referidos a ciudadanía, es decir, a las relaciones de los sujetos con la política y el Estado, comparados con aquellos referidos al civismo o las relaciones sociales interpersonales, intra-grupo o locales. Por último, cuál es la visión en el currículo del pasado y del futuro de la sociedad en cada caso -observable en su tratamiento de la historia nacional-, relato clave para la identidad y la cohesión.

Estas interrogantes dieron lugar a las siguientes cuatro categorías analíticas, que se utilizaron para examinar comparativamente los currículos de los siete países de la región referidos.

- La primera categoría, Sociedad y nación, contiene las definiciones de los distintos currículos de los países sobre la idea de sociedad mayor que articula el currículo, y de si el referente vinculante del conjunto es o no el concepto de nación.

- La segunda categoría, Historia, rescata las relaciones con la propia historia que el currículo escolar busca comunicar a la nueva generación. Esta puede ser celebradora de un origen y trayectoria que es base de identidad y unidad, o estar ausente como referencia, $y$, en cambio, el referente de identidad y unidad estar en el futuro, como proyecto a construir. Hay en esta polaridad un sentido adicional: la historia como mito, o la historia como base de reflexividad (Koselleck 1993; Wineburg 2001). 
- La tercera categoría, - Ciudadanía, se refiere a la presencia e importancia relativa de objetivos y contenidos relacionados con la formación ciudadana o educación cívica tradicional: la preparación para la participación política a través de la educación en el conocimiento y valoración de las instituciones y procedimientos constitutivos de la organización democrática del poder. En términos de las distinciones sobre capital social mencionadas al inicio, ¿cuánto hay en el currículo directamente conectado con la preparación en las competencias para el capital social puente?

- La cuarta categoría de descripción y comparación de los currículos, Civismoconvivencia, rescata la presencia e importancia relativa (en especial comparada con la categoría anterior) de objetivos y contenidos referidos a la sociabilidad primaria como a las relaciones en grupos locales o comunitarios. En términos de tipos de capital social, la categoría rescata objetivos y contenidos orientados a formar en las competencias del capital vinculante.

\section{Análisis y Resultados}

La Tabla 2 sintetiza, respecto de cada una de las categorías mencionadas más arriba, los resultados de un análisis de contenido de los currículos oficiales de Argentina, Brasil, Chile, Colombia, Guatemala, México y Perú, para los grados finales del nivel primario (Cox, Lira y Gazmuri, 2007).

Es posible dar cuenta del conjunto de prescripciones curriculares de los países y su comparación en términos del modelo que se plantea a continuación. Esto es clave para conocer la visión que la educación busca inculcar acerca de la sociedad y de la comunidad simbólica, que son base de la cohesión societal. El modelo propuesto se articula sobre la base de dos ejes, los que generan un espacio de posiciones que dan cuenta de las similitudes y diferencias más importantes en las orientaciones de cada currículo nacional respecto de objetivos y contenidos educativos:

- El eje vertical (Figura 1) corresponde a la dimensión relacional de la vida en común para la que forma el currículo. Los polos son Civismo-convivencia (extremo inferior) y Ciudadanía-política (extremo superior). Como se ha mencionado, en este último corresponde ubicar a los currículos que enfaticen objetivos y contenidos curriculares referidos al Estado, la política y las relaciones de los individuos con el sistema político (capital social puente), mientras que en el polo de Civismoconvivencia corresponde a los currículos que, como contrapartida, privilegien objetivos y contenidos orientados a formar en competencias para las relaciones interpersonales, intra-grupo, locales y comunitarias (capital social vinculante). ${ }^{9}$

- El eje horizontal corresponde a la dimensión identidad. Aquí los polos son Afirmación de la nación-experiencia histórica, ${ }^{10}$ por un lado, y Valores universalesexpectativas de sociedad, por el otro. Mientras hacia el primer polo corresponde ubicar a los currículos que enfatizan una memoria común, cuya base se encuentra en el pasado histórico y que refieren a la nación como principio identitario, en el polo opuesto corresponde ubicar a los currículos que comunican una visión que es crítica tanto del pasado como del presente, y que fundan el referente identitario en una expectativa futura o en un proyecto de sociedad. 


\begin{tabular}{|c|c|c|}
\hline 晃 & 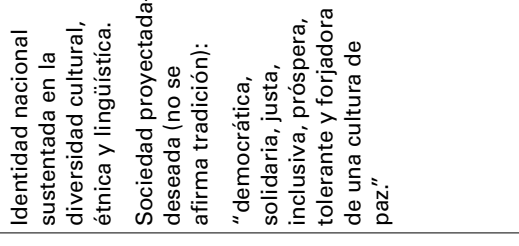 & 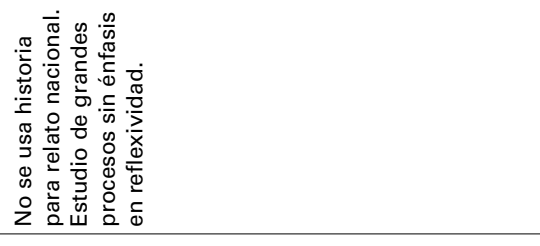 \\
\hline & 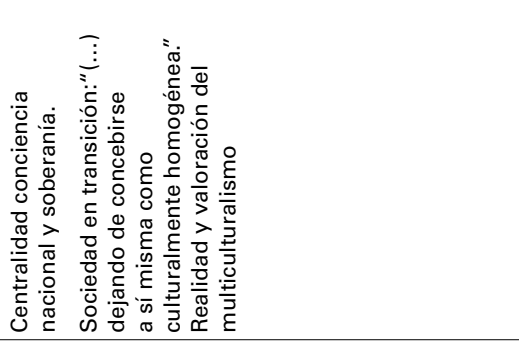 & 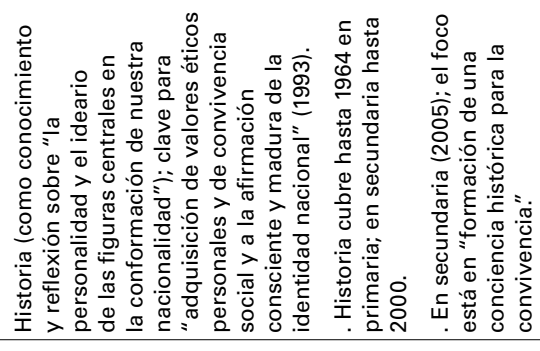 \\
\hline & 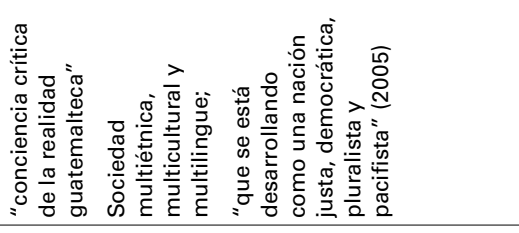 & 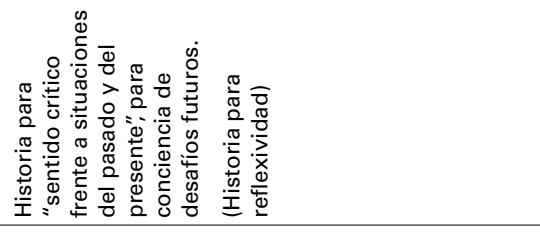 \\
\hline & 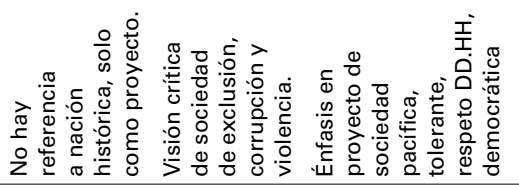 & 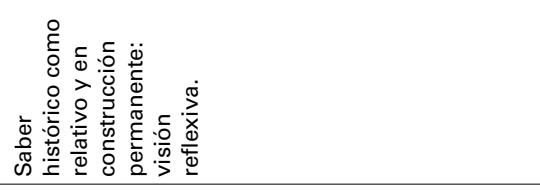 \\
\hline$\frac{\varrho}{\overline{\underline{E}}}$ & 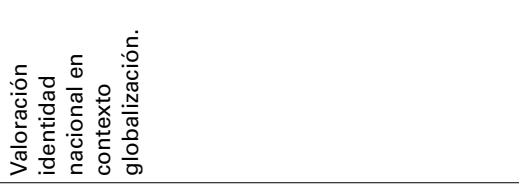 & 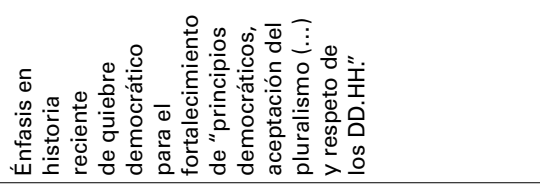 \\
\hline 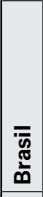 & 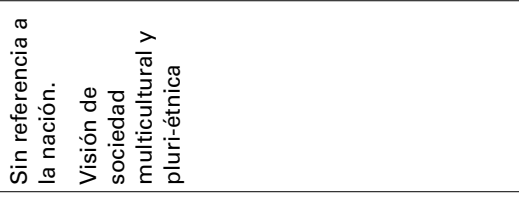 & 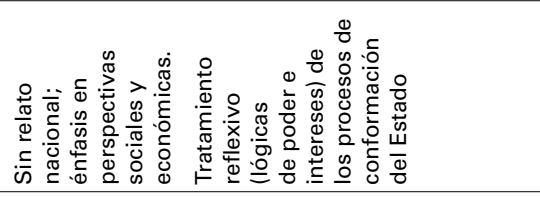 \\
\hline & 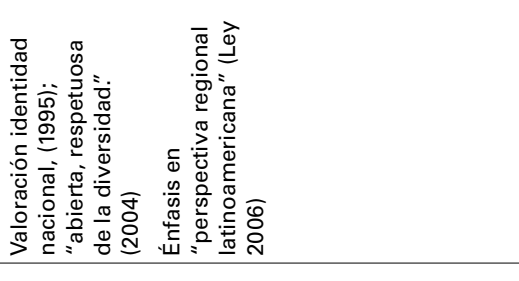 & 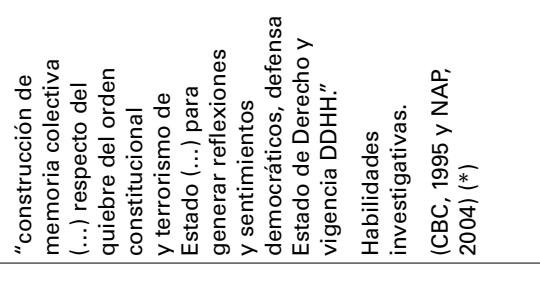 \\
\hline & 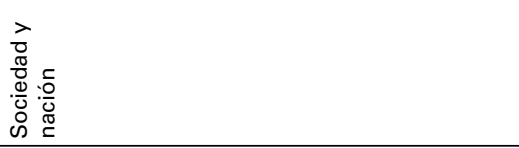 & 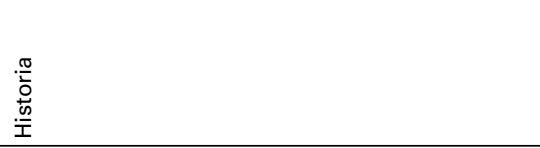 \\
\hline
\end{tabular}




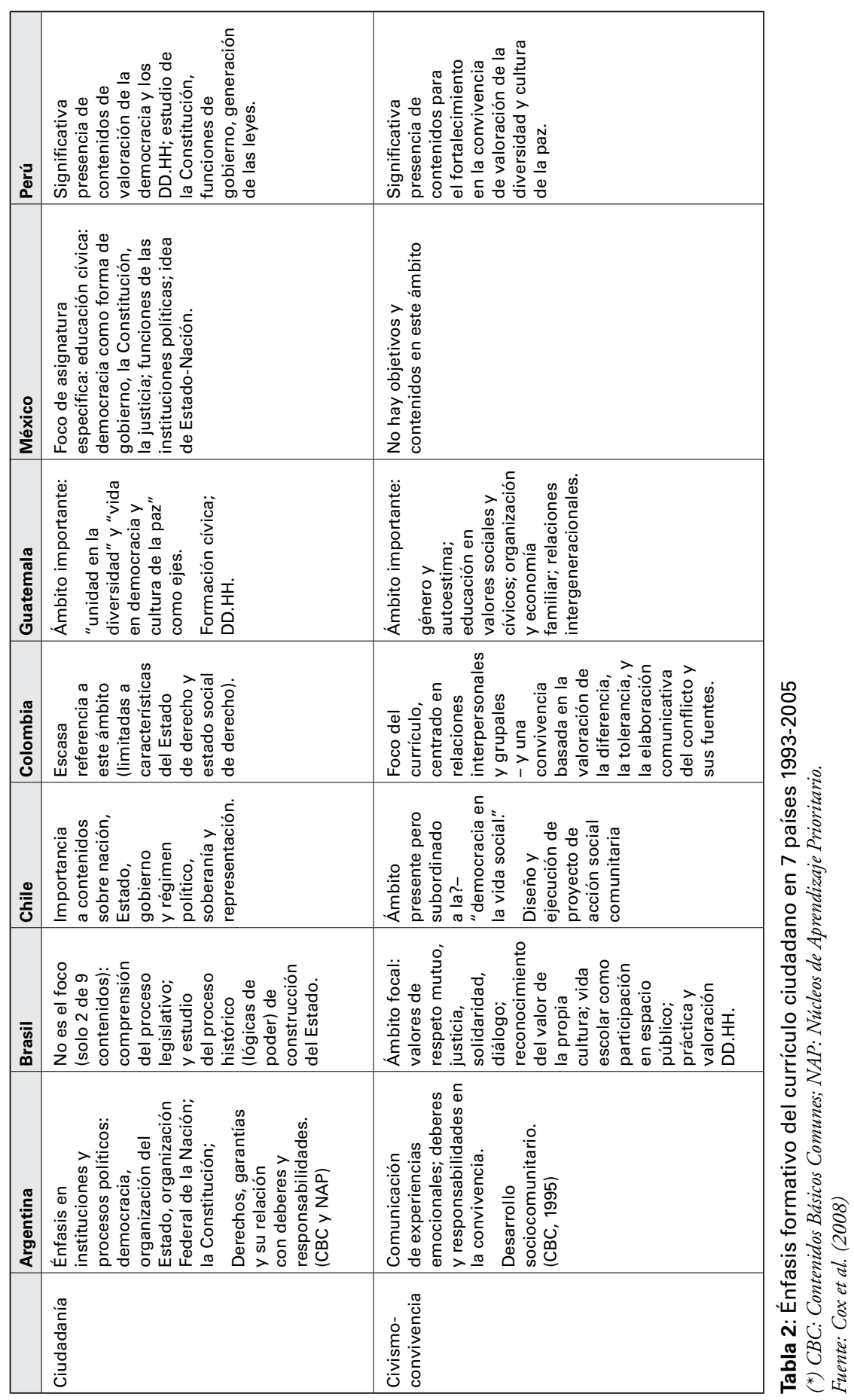


Los ejes y sus polos generan un espacio de posiciones que permite distinguir entre los currículos de los países y considerar, desde la ubicación de cada uno, las interrogantes sobre el significado de cada uno para las oportunidades de aprendizaje funcionales a la cohesión social de sus respectivas sociedades. En la Figura 1, se ordenan los currículos de los diferentes países según su posición respecto de los dos ejes aludidos.

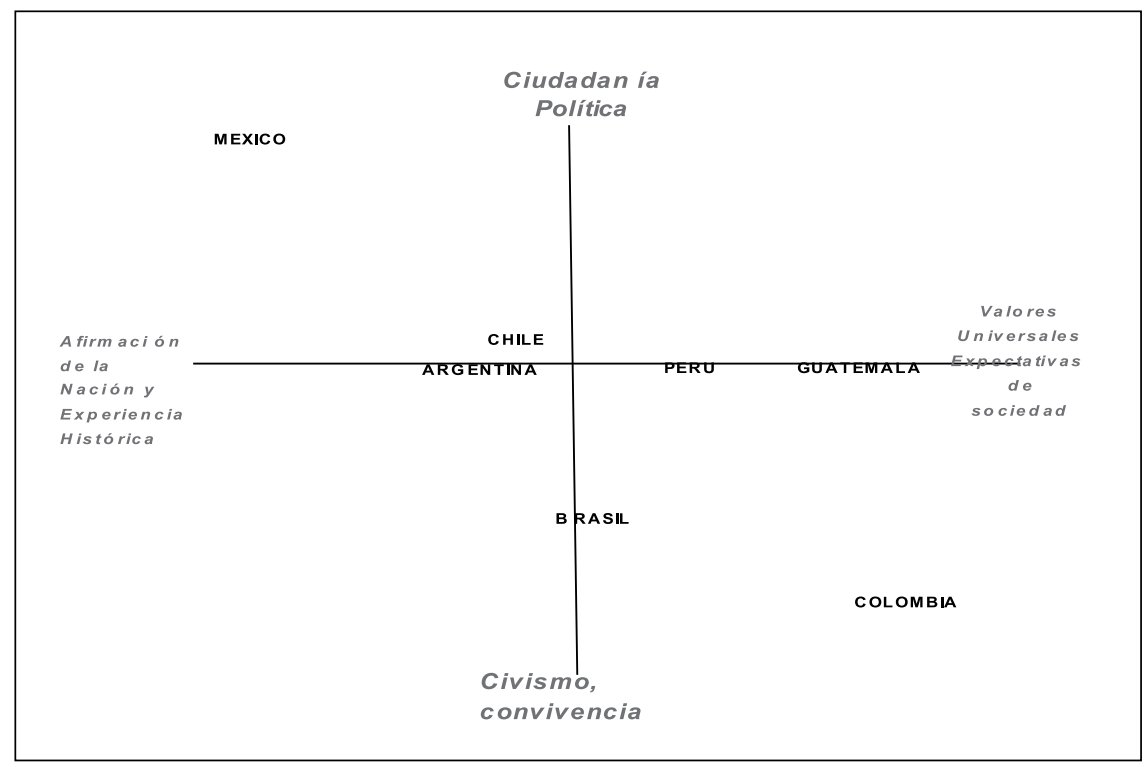

Figura 1: Referentes clave para la formación de identidad y capital social en los currículos vigentes de educación primaria de 7 países Latinoamericanos: diagrama de posiciones.

México (currículo de primaria, 1993), que se ubica en el cuadrante superior-izquierdo, está en la posición más cercana del polo Afirmación de la nación-experiencia histórica, en el eje identidad, y Ciudadanía-politica, en el eje relacional. Su currículo celebra explícitamente a la nación como principio identitario, y plantea una asignatura especial para ciudadanía (política), con práctica ausencia de objetivos y contenidos sobre civismo y convivencia. Respecto de México debe tenerse presente, sin embargo, que hay una marcada diferencia entre el currículo vigente en 2007 para la educación primaria -generado por una de las últimas administraciones del PRI hace 15 años-, y el de secundaria, definido en 2005 por la administración del Presidente Fox, abierto al multiculturalismo y una visión de identidad menos unitaria y primordial ${ }^{11}$ respecto a la nación.

Argentina y Chile se ubican en el eje vertical en una posición más cercana al polo Ciudadania-politica que al de Civismo-convivencia, aunque sus definiciones abordan ambas dimensiones de la dimensión relacional. En el eje horizontal se ubican también en el centro, aunque más cerca del polo Afirmación de la nación-experiencia histórica, porque en sus currículos tratan el pasado como definitorio de identidad, pero con una 
visión más crítica que México, al tratar en sus currículos expresamente los períodos autoritarios y de atropellos a los Derechos Humanos, pero claramente valoradores de una experiencia histórica más larga, que los distancia nítidamente de los currículos de Perú, Guatemala y Colombia. Asimismo tienen algo de proyecto y aspiración en sus definiciones sobre equidad, justicia y desarrollo.

Perú y Guatemala no se distinguen de los países del Cono Sur respecto al eje vertical, pero sí claramente respecto al eje horizontal. Se trata en ambos casos -más marcadamente en el currículo de Guatemala- de definiciones de objetivos y contenidos que comunican una visión muy crítica de su sociedad, y donde las expectativas de transformación de la misma y del futuro son las dimensiones que estructuran el espacio simbólico común. ${ }^{12}$

Brasil en el eje vertical se encuentra en una posición más cercana de Civismoconvivencia que a Ciudadanía-política, ya que su currículo de básica de 1998 prácticamente ignora el sistema político y las relaciones ciudadanas, para centrarse por completo en relaciones locales y comunitarias. Al igual que Colombia, es como si a la escuela sólo le preocupara crear las bases culturales y conductuales del capital social vinculante y no el de puente. En el eje horizontal, el currículo de Brasil se ubica un poco más hacia el polo Valores universales-expectativas de sociedad en comparación con Argentina y Chile, por su talante más crítico y de transformación sociocultural que el de estos dos países.

Colombia en el eje vertical representa el caso más radical de foco en relaciones interpersonales y de la sociabilidad primaria, como base de creación de confianzas y manejo pacífico del conflicto, sin referencia al ámbito político. En el eje horizontal, puede considerarse su currículo como en la posición antípoda de México: nada que celebrar del pasado ni del presente: el referente identitario que la educación debe trabajar es claramente el de las expectativas, el de un proyecto de transformación.

Simplificando, puede plantearse que hay dos situaciones fundamentales, en torno a las cuales se dan las variaciones nacionales: i) la del cuadrante superior-izquierdo, donde están México y los dos países del cono sur. A estos se los puede calificar como tradicional, en términos de que se trata de currículos y sistemas escolares de sociedades relativamente cohesionadas, en un sentido que ni Colombia, Guatemala ni Perú parecen serlo, y donde el referente identitario es la nación y su historia, así como un foco explícito en formación para la ciudadanía (capital social puente); ii) la del cuadrante inferior-derecho, donde figuran Perú, Guatemala, Brasil y Colombia, aunados por omitir una referencia respecto de la nación, significado que es llenado por la referencia a valores universales, y omisión también respecto a la historia como referente identitario. Los currículos de Brasil y Colombia además se distinguen por su omisión respecto a la institucionalidad democrática y la preparación para la participación política (o capital social puente).

\section{Declive de la Nación como Referente}

La definición de la comunidad respecto a la cual niños y jóvenes son educados para que la sientan como propia, y a la cual deben su adherencia y lealtad, sin duda que 
es una de las tareas centrales y clásicas de la escuela. Históricamente, el referente crucial para esta construcción escolar de identidad ha sido la nación. ${ }^{13}$ Los currículos de la década de 1990 en Latinoamérica se ubican claramente en otra perspectiva respecto a la nación, el Estado y el patriotismo. Llama a reflexión cuán tenue es la presencia de la nación como referente de lo colectivo en los currículos del cuadrante inferior-derecho. Y cuán problemática puede ser esta ausencia, porque si no hay una construcción cultural de la nación en el sistema escolar, en su sentido más profundo de comunidad de origen y destino, se está ante el riesgo de tendencias disgregadoras de lo común, fuertemente presentes tanto en la lógica del mercado como en el clima cultural valorizador de la diversidad.

Lo que ha sustituido a la nación como referente del imaginario común en los currículos escolares apunta, simultáneamente, más abajo y más arriba: "más abajo", en el sentido de grupos sociales, de base local o étnica; y "más arriba", en el sentido de que la Declaración de los Derechos Humanos, en su universalidad y precedencia sobre las definiciones de Estados particulares, redefine el locus de la regulación moral de la política, subordinando la nación a la humanidad.

Este "deslizamiento hacia lo universal" 14 tiene una génesis más global que la de contextos regionales y que la de los países en que se basa este análisis. Un examen comparativo reciente de tendencias del currículo para la ciudadanía en Europa y Asia detecta un cambio en el modelo del buen ciudadano: de uno basado solamente en normas colectivas nacionales a uno crecientemente basado en normas transnacionales (Soysal y Wong 2006). Es más, en un análisis de tendencias mundiales que afectan al currículo escolar en el cambio de siglo, el sociólogo de Stanford, John Meyer (2005), destaca la práctica desaparición del Estado-nación como referente primordial de la formación ciudadana en el currículo escolar de la mayoría de los países, con independencia de culturas y grados de desarrollo.

La conjunción de influencias globales, como las aludidas, con historias nacionales y desarrollos específicos de los campos educativos del caso, conforman un entretejido complejo que nítidamente está produciendo en los currículos de los países una transición de vastas implicancias para las bases culturales de la cohesión social. Más allá de las diferencias sistemáticas observadas, hay un cambio de fondo respecto a cómo se han respondido tradicionalmente dos interrogantes nodales: ¿cuál es el núcleo simbólico común que une a los diferentes? ¿Cómo se prepara para interactuar con los distantes? El declive de la nación como referente interroga sobre el poder vinculante de sus reemplazos (valores universales como los derechos humanos o ciudadanía global). Adicionalmente, la omisión respecto a las instituciones políticas y la ciudadanía de varios de los currículos nacionales estudiados interroga frontalmente sobre su funcionalidad para la cohesión en contextos democráticos.

\section{Jóvenes Latinoamericanos, Nuevos Currículos y Política Democrática}

El desencanto de los jóvenes con la política, corriente que es mundial en la cultura globalizada (World Bank 2006), junto con la disminución objetiva de los poderes de aquella frente al capital globalizado en el marco del Estado nacional, desafían 
a la educación a actuar contracorriente para formar en la valoración de la política. Ningún sistema institucional sobrevive sin ser sostenido por una voluntad de vivir juntos, y cuando esa voluntad se pierde, toda la organización política corre el riesgo de desvanecerse (Ricoeur 1984). Sin embargo, como ilustró el análisis de los currículos, pareciera que no se está educando para querer los asuntos de la ciudad (la sociedad) en su conjunto, sino para la celebración de la diversidad y el pluralismo sociocultural y para apreciar los valores del grupo o comunidad inmediata, por un lado, y del mundo global, por el otro.

Debiera ser de especial preocupación para los educadores el distanciamiento de los jóvenes con la política y la esfera pública. De acuerdo con el estudio de opinión sobre la democracia en Latinoamérica llevado a cabo por el Programa de las Naciones Unidas para el Desarrollo (PNUD 2004), ${ }^{15}$ la edad es un factor discriminante respecto a orientaciones hacia la democracia. Una proporción significativamente alta de jóvenes del grupo de 16 a 29 años (el grupo con mayor escolaridad de los comparados), tiene orientaciones no-demócratas (28,7\%); un 31,2\% corresponde a la categoría ambivalentes y un $40,1 \%$ tiene orientaciones demócratas. ${ }^{16}$

La evidencia proveniente de una comparación de conocimiento y disposiciones cívicas entre estudiantes de secundaria de Colombia, Chile y Estados Unidos, patrocinado por la Organización de Estados Americanos, muestra que los jóvenes en el presente participan mayoritariamente en organizaciones comunitarias y solidarias, a la vez que manifiestan su desconfianza y distancia respecto a las instituciones y la participación política. Su compromiso social está desconectado de la valoración y el compromiso con la política y los procedimientos y exigencias de la democracia (Torney-Purta y Amadeo 2004). Un estudio de opinión de fines de la década pasada en Costa Rica, Chile y México, constató la atribución de parte de los jóvenes de un significado diferente a la democracia que la generación adulta: los jóvenes otorgaron importancia a los problemas de la diversidad y la protección de las minorías políticas, mientras la generación adulta identificó democracia con conceptos de orden y competencia electoral (Ai Camp 2001).

Todo indica, en suma, que pareciera necesario velar porque el nuevo énfasis en ciudadanía social (o civismo), que responde además a motivos profundos en la cultura de los jóvenes como la preocupación por la diversidad y el compromiso solidario con grupos inmediatos (Ai de Camp 2001; Torney-Purta y Amadeo 2004), no vaya en desmedro del tratamiento de objetivos y contenidos referidos a institucionalidad y ciudadanía política.

\section{Conclusiones}

Examinar las políticas educacionales y la evolución reciente de los sistemas escolares de América Latina desde la perspectiva de la cohesión social, ofrece una nueva mirada sobre ambas. Distinta y complementaria en algún sentido de la que arroja la mirada, más frecuente, desde criterios de equidad. Y con hallazgos que sugieren pistas nuevas a la investigación así como levantan caveats también nuevos a las políticas.

La evolución en la última década y media de los sistemas escolares de la región, ¿̨ha 
contribuido a la cohesión social de sus sociedades?; ¡cuáles han sido los impactos de las políticas educacionales sobre tal evolución?

Respecto de la distribución de la educación, la última década y media ha presenciado una expansión sustancial de la experiencia educacional común: más personas han tenido experiencias educativas más largas y más similares entre ellas. Ha habido aumentos absolutos en la cantidad de educación en toda la región, por prolongación de la educación obligatoria y expansión de las coberturas, que al mismo tiempo han mejorado la distribución social de la misma, acortando las distancias en años de educación entre el grupo más pobre y el resto. Todo esto con un fuerte impacto intergeneracional.

El conjunto de este dinamismo tiene consecuencias positivas para la cohesión social por tres vías: en primer lugar, por la expansión de lo común en términos de capacidades, experiencia y lenguajes de las personas, fundamento de los mecanismos de la confianza y la cooperación social; en segundo lugar, por el alza del nivel educativo de grupos amplios que son capaces de culminar la educación secundaria alta, nivel educativo donde se comienzan a verificar alzas consistentes en la proporción de personas cohesivas; en tercer lugar, por el impacto de las dimensiones intergeneracionales de estos cambios sobre las expectativas. Como también fue recogido por la encuesta ECosociAL-2007, la movilidad educacional intergeneracional es replicada en forma clara en la percepción de oportunidades educativas y en altas expectativas al respecto, las que atraviesan la estructura social, lo cual tiene importantes consecuencias sobre las percepciones de legitimidad de la distribución de los recursos en la sociedad (Schwartzman 2008).

Las políticas de los gobiernos orientadas a priorizar y aumentar el gasto en educación e implementar los programas focalizados en pobreza están en la base de los efectos comentados: no se habría podido aumentar las coberturas de la educación secundaria, por ejemplo, sin mayores recursos; ni probablemente se habría producido el acortamiento de la brecha educativa, en términos de la completación de estudios del nivel primario del grupo más pobre, sin los programas focalizados. Al mismo tiempo, las políticas están respondiendo a la demanda social por educación percibida por todos los grupos como vía de ascenso y de oportunidades, así como a una nueva visión de los grupos dirigentes respecto del papel estratégico de la educación para el desarrollo y la integración en contextos globalizados.

El eje de descentralización de las políticas es el más equívoco en términos del criterio de cohesión social. Puede que sus impactos sobre participación en las decisiones de los grupos locales y mejoras en accountability hayan contribuido a mejorar la relevancia de la oferta educativa y, por esta vía, producido mejoras de los sistemas escolares en su capacidad de retener alumnos de grupos que en un momento anterior desertaban tempranamente. Pero grosso modo, sus objetivos y justificación están en otra lógica - de reasignaciones de poder y mejoras en la eficiencia-, que frente al criterio de cohesión social, y sus requerimientos de extensión de condiciones niveladas y socialización común se revelan como problemáticas. Hay aquí, sin duda, una necesidad mayor de evaluación y discernimiento político acerca de los bienes en juego y su ponderación relativa. 
En lo que respecta al currículo, la respuesta a las interrogantes sobre la evolución de los sistemas escolares de la región en la última década y media y el impacto en la misma de las políticas de reforma curricular, el balance que emerge es problemático. Tres tendencias observables en los datos y su análisis respaldan esto:

- Los currículos en general muestran un declive consistente de la presencia de referentes simbólicos fuertes de lo común. Lo más claro al respecto es la tendencia a la sustitución de la nación, sea por omisión o por la referencia a valores universales o globales y la celebración de la diversidad y lo local, en desmedro de las referencias al conjunto.

- En varios de los casos nacionales examinados, los currículos no confieren importancia a la educación ciudadana -a la relación con el Estado y la política. Son deficitarios entonces en la formación de conocimientos y disposiciones para formar el capital social puente, sin el cual no se puede concebir la cohesión social en sociedades diferenciadas y complejas.

- Asimismo, en varios de los casos comparados, la experiencia histórica no parece ser base para la construcción de la identidad y de las solidaridades horizontales, pues el pasado ha sido reemplazado por las expectativas de futuro. Esto plantea dudas - de modo similar a lo que ocurre con la erosión de la apelación a la nación - sobre el poder cohesionador de este referente.

Dos tipos de evidencia generada por la encuesta ECosociAL-2007 ayudan a visualizar el contexto sociocultural mayor en que trabaja la institución escolar y dan significado adicional a los riesgos para la cohesión social de las tendencias referidas. Primero, el alto nivel de alienación respecto a gobiernos y autoridades políticas que expresan las personas, que más que duplica, para todos los países estudiados, las tasas de exclusión (Valenzuela et al. 2008): desde la perspectiva de la cohesión societal, esto es un riesgo serio que llama a respuestas desde la educación. Segundo, el retroceso de la proporción de "cohesivos" de la generación anterior a la actual, comprobada con precisión para distintos niveles educativos, tanto por ECosociAL-2007 como por Latinobarómetro. Probablemente, se está frente a efectos socioculturales del tipo de los estudiados por Putnam en Bowling Alone-desde el impacto de la TV hasta cambios en el mundo del trabajo, la familia y el reemplazo de una generación más socialmente orientada por una más individualistamente orientada. Ambos tipos de evidencia hablan de necesidades de contrarrestar riesgos para la cohesión que parecen no haberse visualizado, y que ni las reformas curriculares ni las políticas sobre docentes o gestión escolar hasta ahora han abordado explícitamente.

La ausencia o debilidad de la educación ciudadana en algunos países (relación con la institucionalidad estatal y los procedimientos políticos democráticos), y su reemplazo por educación en relaciones de civilidad interpersonal o intra-grupal, merece ser estudiada y tematizada públicamente en profundidad. Es difícil exagerar la urgencia de hacer parte del discurso acerca de la educación esta situación: especialmente en la arena de políticas públicas como en la de formación de profesores. En contextos de marcada desigualdad social y debilidades institucionales de la política democrática, que caracterizan a muchos contextos nacionales de la región, el contrarrestar desde la 
educación las profundas tendencias anti-políticas de la cultura de mercado y la aceleración de los procesos de individuación sin contrapesos que la acompañan, parece esencial.

Un sistema escolar nacional es el resultado de un enorme proceso de reflexividad socio-política mediante el cual una sociedad decide, más o menos cooperativa o conflictivamente, cómo formar a la nueva generación. Es, por cierto, la interrogante más fundamental a la política si nuestras sociedades quieren ir en la dirección estructuralmente modelada por el dinamismo global de la economía y la cultura que la acompaña, o, en vez, trabajarán para navegar trayectorias más elegidas y construidas que sobrellevadas. Esto supone contrarrestar el poder de las tendencias que han sido caracterizadas como de riesgo para la cohesión social, y creer en las posibilidades de la apropiación histórica y el dominio de las mismas a través de la política democrática. Quizás sea la formación en esta creencia una buena base de inspiración para el trabajo de los educadores, así como para la formulación de políticas públicas en educación.

\section{Notas}

1. El artículo se funda en resultados de investigación sobre educación y cohesión social elaborados en el marco del proyecto Nueva agenda para la cohesión social en América Latina, de los centros de investigación CIEPLAN (Santiago de Chile) e iFHC (Sao Paulo, Brasil). Para una versión inicial del argumento, ver trabajo de C. Cox, en Eugenio Tironi (editor), 2008, Redes, Estados y Mercados. CIEPLAN, iFHC. Santiago: Uqbar Editores.

2. Estos países fueron los estudiados por el proyecto 'Nueva Agenda para la Cohesión Social en América Latina' mencionado, En los mismos se aplicó la encuesta ECosociAL-2007. Un análisis detallado de los resultados se encuentra en Valenzuela et.al 2008. Ver también www.ecosocialsurvey.org

3. Se ha traducido bonding capital como capital vinculante; bridging capital, como capital puente. Cabe observar que esta misma distinción de Putnam es trabajada en la literatura en términos de la diferencia entre confianza generalizada o confianza social respecto de personas o instituciones desconocidas, y la confianza particularizada o interpersonal.

4. Sobre la circularidad de los argumentos respecto a capital social y cohesión social, Baron et al (2000) se interrogan como sigue: “¿Es el capital social una característica de una sociedad floreciente o el medio de lograrla? ¿Es un instrumento, un resultado o un desideratum? El capital social es criticado por su circularidad, siendo utilizado tanto como variable explicativa, por ejemplo, en relación a la cohesión social, y como descriptor del mismo fenómeno. (...) Pero se puede argumentar, desde una perspectiva diferente, que el abordaje de capital social es relacional, y nos requiere mirar los fenómenos sociales desde diferentes ángulos simultáneamente de maneras que al menos intenten capturar la naturaleza cambiante de las relaciones. (...) Tales relaciones no pueden ser captadas por ninguna línea de análisis particular, tal como la física nos dice que no se puede medir la velocidad y la posición al mismo tiempo" (Baron et al. 2000: 29).

5. El puntaje mínimo es 0 si un individuo dice no poseer ninguna de las características referidas y el máximo es 4 si un individuo las posee en gran o bastante medida (dependiendo de la escala usada por cada una de las cuatro variables originales). El porcentaje de los individuos con un valor 3 o 4 se usa como el índice de cohesividad. 
6. "Los libros del docente en México, los artículos didácticos del Monitor de la educación común en la Argentina, fueron ejemplos de lo explícitas que eran esas directivas y las formas bajo las cuales eran presentadas. También podemos pensar en que la puntualidad de las directrices didácticas se debía a la evaluación de la escasez de recursos humanos capacitados puesto que, como resulta obvio, era muy difícil capacitar al mismo ritmo que requería un sistema con altísimo grado de crecimiento. La falta de maestros obligaba a incorporar idóneos, o maestros de muy bajo nivel de formación. Mientras los sistemas desarrollaban dispositivos de formación, requerían de perfiles que asumieran las tareas del aula, y la debilidad de algunos de esos perfiles podría explicar la decisión de entregarles "guiones" pautados de lo que debía ocurrir en las aulas" (Iaies y Delich 2007: 18).

7. Educación y conocimiento: eje de la transformación productiva con equidad (CEPALUNESCO 1992) es probablemente el documento de mayor influencia en el pensamiento de las élites gubernamentales responsables de las más importantes reformas de sistemas educativos en la región en la década de 1990.

8. Como se recordará, el índice de cohesividad fue propuesto por Crouch et al. (2007), e incluye los siguientes indicadores: (1) la confianza que el individuo dice tener en los otros; (2) el sentirse parte de una mayoría; (3) el trabajar por iniciativas comunitarias; y (4) el orgullo patrio.

9. Los dos polos de este eje se corresponden directamente con lo que la encuesta ECosociAL-2007 distingue y mide a través de las categorías Exclusión (medida por tres preguntas sobre relaciones con la gente que me rodea) y Alienación (medida por tres preguntas acerca de las autoridades o la gente que dirige el país). Veáse Valenzuela et. al (2008).

10. “(...) la experiencia es un pasado presente, cuyos acontecimientos han sido incorporados y pueden ser recordados"; (...) la expectativa es futuro hecho presente, apunta al todavía-no, a lo no experimentado, a lo que solo se puede descubrir.” (Koselleck 1993: 338). Para este filósofo de la historia “(...) en la época moderna va aumentando progresivamente la diferencia entre experiencia y expectativa, o, más exactamente, que solo se puede concebir la modernidad como un tiempo nuevo desde que las expectativas se han ido alejando cada vez más de las experiencias hechas" (Koselleck 1993: 343).

11. Término con que la literatura comparada sobre educación ciudadana caracteriza la visión tradicional de la nación, fundada, al decir de Renan (1996), en el acuerdo de recordar ciertas cosas del pasado y olvidar otras. Bauman va un paso más lejos: "Yo aguzaría el punto un tanto: el nacionalismo prescribe que todas las cosas sobre las que no se acuerda que sean recordadas debieran ser olvidadas" (Bauman 1999: 164). Visión en retroceso mundial (cfr. Soysal y Wong 2006).

12. Parafraseando a Koselleck, se diría que se trata de currículos que entre los dos modos de ser -el recuerdo y la esperanza-, cuyo entretejido constituye la historia, se centran casi completamente sobre el segundo (Koselleck 1993).

13. "La nación es un arco de solidaridades, una construcción po lítica e ideacional que postula la existencia de un 'nosotros' que entraña un reclamo de lealtad por encima y más allá de otras identidades e intereses y que, si ya no la tiene, frecuentemente busca asentarse o definirse en un territorio delimitado por el Estado." (O’Donnell 2004: 165).

14. Expresión de Francois Audigier al analizar el currículo para la ciudadanía de Francia: el deslizamiento hacia la universalidad hizo que en Francia, la patria, la nación, no fueran referencias sistemáticas, obligadas del currículo (Audigier 1999).

15. El estudio se basa en una encuesta de opinión respondida por 18.643 ciudadanas y ciudadanos de 18 países: Argentina, Bolivia, Brasil, Chile, Colombia, Costa Rica, Ecuador, El Salvador, Guatemala, Honduras, México, Nicaragua, Panamá, Paraguay, Perú, República Dominicana, Uruguay y Venezuela. 
16. Los ambivalentes son personas con concepciones delegativas de la democracia. "Están en principio de acuerdo con la democracia, pero creen válido tomar decisiones antidemocráticas en la gestión de gobierno si, a su juicio, las circunstancias lo ameritan." (PNUD 2004: 134).

\section{Referencias}

Ai Camp, Roderic. (2001). Citizen Views of Democracy in Latin America. University of Pittsburgh Press.

Audigier, François. (1999). Instruction civique, éducation civique, éducation a la citoyenneté. Education aux citoyennetés... Changement du nom. Changement du contenu? Vers une citoyenneté européene. (Journées d'étude). Paris: CNDP.

Baron, Stephen; John Field, and Tom Schuller. (2000). Social Capital. Critical Perspectives. Oxford: Oxford University Press.

Baumann, Zygmunt. (1999). In Search of Politics. California: Stanford University Press.

Braudel, Fernand (2002) El Mediterráneo y el mundo mediterráneo en la época de Felipe II. México: Fondo de Cultura Económica.

Carnoy, Martín. (2007). Improving quality and equity in Latin American education: a realistic assessment (Pensamiento Educativo No 40). Santiago: Facultad de Educación Universidad Católica de Chile.

Carnoy, Martín; Gustavo Cosse; Cristián Cox, y Enrique Martínez Larrechea. (2004). Las reformas educativas en la década de 1990. Un estudio comparado de la Argentina, Chile y Uruguay. Buenos Aires.: Ministerios de Educación de Argentina, Chile y Uruguay, Grupo Asesor de la Universidad de Stanford.

CEPAL-Unesco. (1992). Educación y Conocimiento: eje de la transformación productiva con equidad. Santiago de Chile.

CEPAL. (2007). Panorama Social de América Latina, 2006. Santiago, Chile: División de Desarrollo Social y División de Estadística y Proyecciones Económicas, CEPAL.

Coleman, James, y Thomas Hoffer. (1987). Public and Private Schools: the Impact of Communities. New York: Basic Books.

Collins, Randall. (1994). Four Sociological Traditions. Selected Readings. New York: Oxford University Press.

Comisión Formación Ciudadana. (2005). Informe Comisión Formación Ciudadana (Serie Bicentenario). Santiago de Chile: Ministerio de Educación.

Cox, Cristián; Renato Gazmuri, y Robinson Lira. (2007). El curriculum prescrito y la dimensión formativa de la educación escolar en Latinoamérica: significados para la cohesión social (Documento de Trabajo Proyecto Nacsal). Santiago de Chile: Cieplan-iFHC.

Crouch, Luís; Amber Gove, y Martin Gustafsson. (2007). Educación y Cohesión Social (Documento de Trabajo Proyecto Nacsal). Santiago de Chile: Cieplan-iFHC.

Di Gropello, Emmanuela. (2004). Education Decentralization and Accountability Relationships in Latin America (Policy Research Working Paper 3453): The World Bank.

Dubet, Francois. (2006). El declive de la institución. Barcelona: Gedisa.

Durkheim, Emile. (1977). La educación moral. Buenos Aires: Editorial Losada.

Durkheim, Emile. (1993). Education et Sociologie. Paris: PUF.

Filgueira, Fernando; Juan Bogliaccini, y Carlos Gerardo Molina. (2006). Centralismo y Descentralización como Ejercicio Iterativo. En M. F. F.Filgueira (Ed.), Descentralización de la Educación Pública en América Latina. Río de Janeiro: K. Adenauer Stiftung.

Fukuyama, Francis. (1995). Trust. The Social Virtues and the Creation of Prosperity. New York: The Free Press.

Gajardo, Marcela. (1999). Reformas Educativas en América Latina. Balance de una década. (Documentos PREAL No15). Santiago, Washington: PREAL. 
Green, Andy; John Preston, y Jan Germen Janmaat. (2006). Education, Equality and Social Cohesion: A Comparative Analysis. New York: Palgrave.

Green, Andy; John Preston, y Ricardo Sabates. (2003). Education, Equity and Social Cohesion: A distributional model (Wider Benefits of Learning Research Report No 7). London: Institute of Education, U. of London.

Grindle, Merilee. (2007). Reform despite the odds: improving quality in education (Pensamiento Educativo $\mathrm{N}^{\circ} 40$ ). Santiago de Chile: Pontificia Universidad Católica de Chile.

Iaies, Gustavo, y Andrés Delich. (2007). Sistemas educativos y cohesión social: La reconstrucción de "lo común" en los estados nacionales del siglo XXI (Documento de Trabajo Proyecto Nacsal). Santiago de Chile: Cieplan-iFHC.

IIPE-OEI. (2006). Informe sobre Tendencias Sociales y Educativas en América Latina. Buenos Aires. : IIPE-UNESCO Buenos Aires y la Organización de Estados Iberoamericanos para la Educación, la Ciencia y la Cultura (OEI).

Kaufman, Robert R., y Joan M. Nelson. (2005). Politicas de Reforma Educativa. Comparación entre Paises (Documentos PREAL N ${ }^{\circ} 33$ ). Santiago, Washington.

Koselleck, Reinhart. (1993). Futuro pasado. Para una semántica de los tiempos históricos. Barcelona: Paidós.

Meyer, John W. (2005). World Models, National Curricula, and Centrality of the Individual. En A. Benavot y C. Braslavsky (Eds.), School Knowledge in Comparative and Historical Perspective. Changing Curricula in Primary and Secondary Education. The University of Hong Kong: Springer.

O’ Donnell, Guillermo. (2004). Acerca del Estado en América Latina Contemporánea. Diez Tesis para Discusión (Texto preparado para el proyecto "La Democracia en América Latina" PNUD): Universidad de Notre Dame.

PNUD. (2004). La democracia en América Latina: hacia una democracia de ciudadanos y ciudadanas. New York y Buenos Aires: PNUD.

PREAL. (2006). Cantidad sin calidad. Un informe del progreso educativo en América Latina. Santiago, Washington.

Putnam, Robert. (2000). Bowling Alone. New York: Simon \& Schuster.

Renan, Ernest. (1996). What is a nation? En G. Eley y R. Grigor Suny (Eds.), Becoming National. New York-Oxford: Oxford University Press.

Ricoeur, Paul. (2004). Projet universel et multiplicité des héritages, en Ou vont les valeurs? Entretiens du XXIe Siécle II (Unesco publication chapter No136615 ). Paris: UNESCO.

Sorj, Bernardo, y Eugenio Tironi. (2007). Cohesión social: una visión desde América Latina. En Cohesión social en Iberoamérica: algunas asignaturas pendientes (Vol. 1, pp. 105-127): Pensamiento Iberoamericano.

Soysal, Yasemin, y Suk-Ying Wong. (2006). Educating Future Citizens in Europe and Asia. En eds. A. Benavot y C. Braslavsky, School Knowledge in Comparative an Historical Perspective. Changing Curricula in Primary and Secondary Education: The University of Hong Kong: Springer.

Torney-Purta, Judith, y Jo-Ann Amadeo. (2004). Fortaleciendo la democracia en las Américas a través de la educación Civica: un análisis empirico que destaca las opiniones de los estudiantes y los maestros. Washington, DC: Organización de los Estados Latinoamericanos.

Valenzuela, Eduardo; Simon Schwartzman; Andrés Biehl, y J. Samuel Valenzuela. (2008). Vinculos, creencias e ilusiones. La cohesión social de los latinoamericanos. Santiago de Chile: Uqbar, Colección Cieplan.

Wineburg, Sam. (2001). Historical Thinking and other Unnatural Acts: Charting the Future of Teaching the Past. Philadelphia: Temple University Press.

Winkler, Don, y Alec I. Gershberg. (2000). Los efectos de la descentralización del sistema educacional sobre la calidad de la educación en América Latina (Documento de Trabajo PREAL, N 17). Washington DC - Santiago de Chile: PREAL. 
World Bank. (2004). Making Services Work for Poor people (World Development Report 2004). Washington DC: The World Bank.

World Bank. (2006). Development and the next generation (World Development Report 2007). Washington DC: The World Bank. 